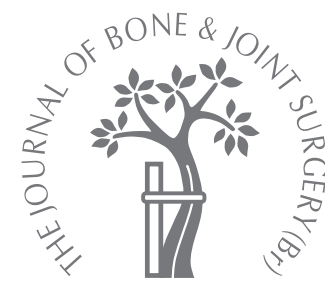

ANNOTATION

\title{
Payment by results and coding practice in the National Health Service
}

\author{
THE IMPORTANCE FOR ORTHOPAEDIC SURGEONS
}

\author{
S. Jameson, \\ M. R. Reed \\ From Wansbeck \\ General Hospital, \\ Ashington, England
}

\begin{abstract}
This paper considers the new financial infrastructure of the National Health Service and provides a resource for orthopaedic surgeons. We describe the importance of accurate documentation and data collection for National Health Service hospital Trust finances and league tables, and support our discussion with examples drawn from our local audit work.
\end{abstract}

Payment by results was introduced across the National Health Service (NHS) in England and Wales in 2005. The system provides a structure of fixed national payment which aims to increase productivity and make better use of hospital capacity. ${ }^{1}$ Payment by results uses Healthcare Resource Groups, similar to those in Europe, the United States and Australia, ${ }^{2-4}$ which group together similar clinical treatments that cost an equivalent amount to deliver. $^{5}$ An individual price, or tariff, is derived for each hospital patient episode (Fig. 1), which is funded by the patient's registered Primary Care Trust.

The data collected for coding include the primary diagnosis, co-morbidity and complications (recorded as ICD-10 codes), the surgical procedure (defined by the OPCS- 4 codes) and the age of the patient. ${ }^{6}$ Computer programmes then derive the health resource group code. The tariff for each resource group represents the average cost of providing a particular treatment. Costs derived nationally from data supplied by NHS Trusts for cemented primary total hip replacement (THR), for example, range between $£ 499$ and $£ 15477$. The average of this ( $£ 5305)$ is used as the national tariff. Minor regional adjustments are made to reflect the cost of living. ${ }^{2}$

Payment by results currently covers all admissions, attendance in the Accident \& Emergency departments and in outpatients departments. ${ }^{7}$ Over $90 \%$ of NHS hospital activity will be funded in this way in $2008 .{ }^{8}$ Poor documentation and inefficient coding can produce incorrect tariffs and hence loss of revenue for the hospital trust. ${ }^{9}$ A lack of interest from clinicians in financial matters has been cited as one of the reasons for the current financial difficulties in the NHS. ${ }^{10}$

\section{The importance of accurate} documentation and data coding

The methods of documentation and data collection are not currently standardised across the NHS. Data are collected from 'source documents', such as clinical case notes, discharge summaries and forms recording the results of investigations. Trusts must ensure that this information is complete and accurate. Audits have consistently identified inadequate documentation as the source of errors in clinical coding, ${ }^{11}$ with levels of error of up to $40 \% .^{12}$ There are inconsistencies between the data recorded in clinical case notes and those found in other documentation. ${ }^{11}$ We sent a postal questionnaire to all NHS Hospital Trusts in England and Wales enquiring about their practice. The coding departments have access to the clinical case notes for every patient episode in only $55 \%$ of trusts.

Our local audit has shown that case notes with thorough, typed entries can produce accurate tariffs. A loss of income of $15 \%$ to $20 \%$ was found when discharge summaries, completed by ward-based nursing and medical staff alone were used ${ }^{13}$ (Fig. 2). To illustrate this, an orthopaedic department with an income of $£ 30$ million per year may lose up to $£ 6$ million because of a coding error. This will have a significant effect on the annual income of the hospital trust.

Surgical patients generate higher tariffs than the average hospital tariff $(£ 1250) .{ }^{14}$ That for a fracture of the neck of the femur ranges between $£ 4518$ and $£ 7936$, depending on the type of fracture and the treatment, co-morbidity and complications. Figure 2 illustrates a loss of revenue of $15 \%$ due to coding inaccuracies, resulting in an average loss of $£ 1061$ per patient. ${ }^{13}$ It has been suggested that the 


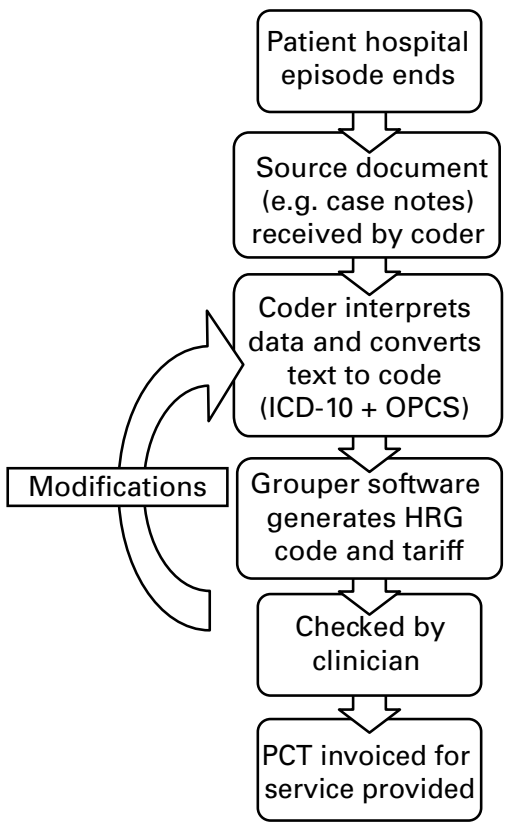

Fig. 1

Diagram of the coding model (HRG, health resource group; PCT, Primary Care Trust).

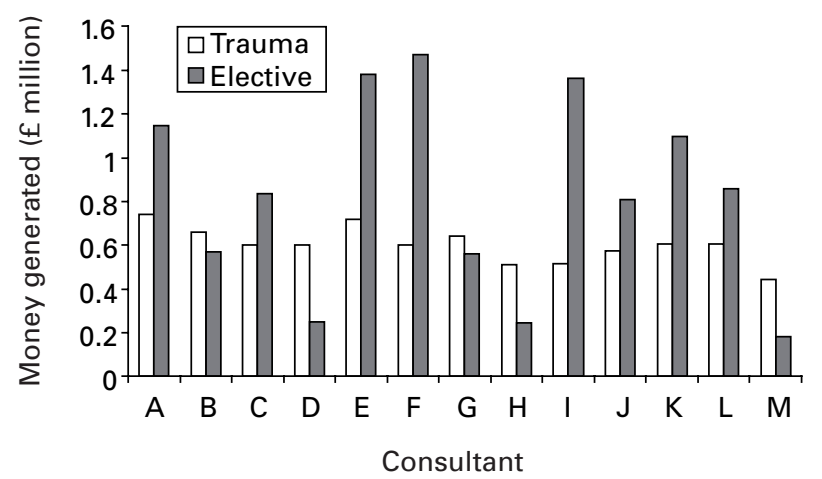

Fig. 3

Barchart showing the income generated under payment by results by 13 consultants at one Trust (Northumbria Healthcare NHS Trust) in one year.

financial deficits encountered in secondary care may be a direct result of a loss of expected revenue from payment by results due to coding inaccuracies. ${ }^{15}$

Dr Foster, league tables and performance-related pay Perhaps of greatest importance for the clinician is the use of this information to create a central database of their results. The Department of Health (DoH) document entitled Good doctors, safer patients ${ }^{16}$ suggested the use of these databases

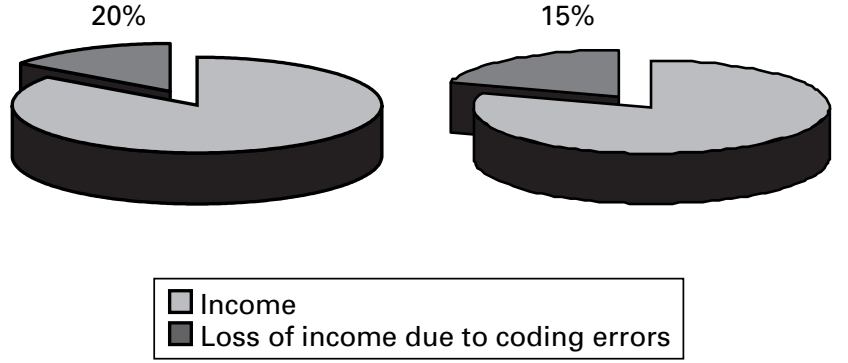

Fig. 2a

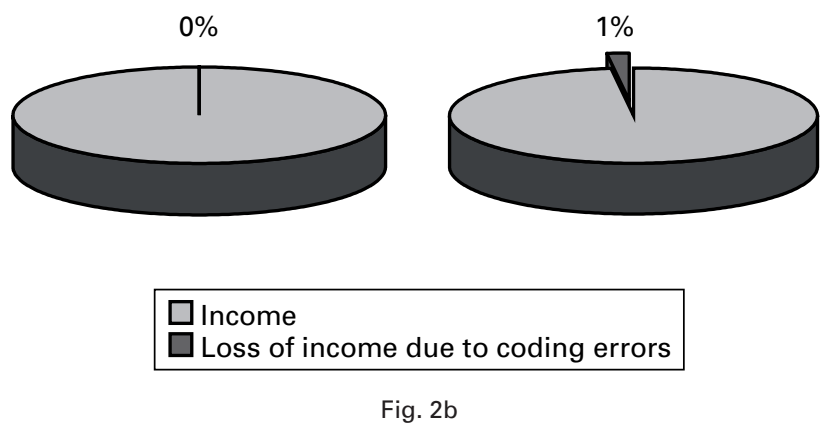

Pie charts showing loss of income due to coding errors in all orthopaedic patients (left) and in those with a fractured neck of the femur (right) a) when discharge summaries are used for coding and b) when clinical case notes are used for coding.

for clinical governance, appraisal and revalidation of hospital consultants. Independent providers of information for the NHS, such as the Dr Foster organisation, have access to data, which is based on submitted coding on all hospital-based care from all NHS hospitals. This information can be used to analyse consultant and hospital clinical performance at local and national levels, and to produce league tables. ${ }^{17}$ Poor coding can produce erroneous figures. The rates for wound infection across NHS hospitals have recently been published in the national press. Those hospitals failing to code accurately may have incorrect rates of infection. With no standardised terms in general use, 'infection' may be coded without microbiological or firm clinical evidence.

Performance-related pay has been proposed in the NHS. ${ }^{16}$ One method of assessing the performance of a clinician is by the income generated for a trust through payment by results. We have analysed this through local audit work for individual orthopaedic consultants, with similar commitments to trauma and elective work, in one trust over a period of one year. These data exclude outpatient activity. The average income generated from trauma was $£ 601000$ and the narrow range between consultants suggested a consistency of workload throughout the year. For elective work, however, the range was much greater, with a mean of $£ 829000$ varying between $£ 183000$ and $£ 1469$ 000. This may reflect the differences in tariffs between sub-specialties, or the individual work intensity of the consultants (Fig. 3). 
Table I. Tariffs for hip procedures and costs of commonly-used implants ${ }^{18}$

\begin{tabular}{|c|c|}
\hline Cemented THR ${ }^{*}$ (tariff, £5305) & $\begin{array}{l}\text { Total implant cost, } £ 1315 \text { (Stryker Exeter, Kalamazoo, Michi- } \\
\text { gan) }\end{array}$ \\
\hline Uncemented THR (tariff, £5091) & $\begin{array}{l}\text { Total implant cost, £3158 (Stryker Accolade/Trident, Kalama- } \\
\text { zoo, Michigan) }\end{array}$ \\
\hline Resurfacing hip arthroplasty (tariff, £4807) & $\begin{array}{l}\text { Total implant cost, } £ 2500 \text { (Smith and Nephew BHR, Memphis, } \\
\text { Tennessee) }\end{array}$ \\
\hline Bilateral primary THR (total tariff, £6496) & $\begin{array}{l}\text { Includes bilateral resurfacing (total cost of implants } £ 5000) \text {, } \\
\text { uncemented THR ( } £ 6316) \text {, cemented THR ( } £ 2630)\end{array}$ \\
\hline $\begin{array}{l}\text { Hemiarthroplasty (no complications or co-morbidities) } \\
\text { (tariff, £5997) }\end{array}$ & $\begin{array}{l}\text { Total implant cost, approximately } f 100 \text { (Thompson's hemi- } \\
\text { arthroplasty, multiple manufacturers) }\end{array}$ \\
\hline
\end{tabular}

\section{Tariffs and the complexity of the system}

The dominant diagnosis or procedural code determines the tariff. A patient who has fixation of a fracture of the neck of the femur and then spends time on a medical ward with complications will generate an orthopaedic health resource group code only. The entire cost of the inpatient episode is paid to the orthopaedic directorate.

Tariffs also vary depending on the type of admission and the length of stay. Additional costs per day are incurred if the average anticipated stay, the trim point, for a particular treatment is exceeded. ${ }^{9}$ Emergency work is generally more costly than elective procedures. Arthroscopy of the knee carries an emergency supplement of $£ 800$, and an emergency amputation generates $£ 10313$ compared with $£ 6229$ for the elective equivalent. ${ }^{18}$

The tariff for new patient episodes in orthopaedic outpatients is $£ 148$, with follow-up attendances generating $£ 73 .{ }^{18}$ No additional payment is currently made for procedures performed in outpatients, yet data collected at one unit in our Trust showed that around 800 joints are injected or aspirated annually in the outpatient department.

Specialised service codes are for those services that are not generally offered at district hospitals and provide a supplement in addition to the tariff for certain procedures. ${ }^{5}$ This may represent a 70\% 'top-up'. This applies to revision THR in the presence of infection, the use of allograft bone for THR, and specialist procedures on the foot and for correction of congenital deformity. This elevates the tariff for revision of an infected THR from $£ 7185$ to $£ 12214$ for each stage. ${ }^{18}$ It is therefore important to extensively document the indication for treatment and the exact procedure undertaken in legible operation notes to ensure accurate coding and recovery of costs.

\section{Problems with payment by results}

This method of payment will create competition between providers to drive down costs, possibly to the detriment of patient care. Tariffs may fall in an effort to lower costs and improve efficiency. Providers who are unable to compete will attract fewer patients and less money. ${ }^{2}$ Trusts that use more expensive materials will be burdened by higher costs and a lower profit margin, even though their use may be justified in increased longevity of the implant or a reduction of the rates of dislocation in hip surgery, for example. Trusts may no longer offer new, expensive treatments which are not proven by long-term evidence. A trust that uses many different prostheses or has a lower workload, and cannot negotiate bulk-buy reductions in cost, may struggle to contain spending within the apportioned tariff. ${ }^{19}$ One study at a large arthroplasty unit in the United Kingdom has shown that, without discounts for the implants, the total cost for performing a cemented THR would be $10.6 \%$ above tariff. ${ }^{19}$ Table I shows the tariffs for certain hip procedures and the costs of commonly-used implants.

Fixed tariffs may be inappropriate at tertiary referral centres. ${ }^{20}$ Several studies in the United States have shown that the tariffs for revision of a THR do not reflect the actual additional costs over a primary procedure and, as such, often result in financial loss. ${ }^{21}$ Smaller units may not offer revision surgery of the hip in the future. ${ }^{9}$ Others will need to support this practice by redistribution of funds within their departmental budget and new equipment, training and education may suffer as a consequence. ${ }^{19}$

\section{Improving the system}

The Audit Commission has observed that payment by results may increase administrative costs by up to $£ 180000$ for each Hospital Trust. ${ }^{22,23}$ These costs represent investment in information technology and long-term increases in staffing in the information, coding and finance departments to ensure better extraction of data and regular audit. ${ }^{22,24}$ Case notes rather than discharge summaries should be the standard means for deriving tariffs. Coding departments need adequate numbers of well-trained staff who can interact with clinicians. ${ }^{25}$ Communication at all levels must improve for the system to be successful. Problems with illegible documentation, an area cited by many coders, should be addressed. 
Newer versions of the health resource group software will provide greater flexibility in the tariffs and some of the current problems should be resolved over time..$^{5}$

Payment by results aims to improve efficiency in the NHS. Accuracy in collection of information and in coding is essential to ensure sound finances for Trusts and to provide reliable central data for monitoring performance. ${ }^{9}$ Coding practices should be standardised nationally and Trusts that perform poorly may need to implement changes. In an effort to drive down costs and increase profits in the system, patient care may suffer. It is of the utmost importance that other performance indicators which are not financially-driven are developed to counteract this.

All the data used in this paper are based on 2007/2008 ${ }^{18}$ reference costs and health resource grouper software version 3.5 (The Information Centre, London, United Kingdom). They aim to illustrate the complexity of the system rather than provide exact figures. More information regarding software updates and changes to reference costs are available from the $\mathrm{DoH}$ Connecting for Health website. $^{26}$

The authors would like to thank the coding, information and finance departments at Northumbria Healthcare NHS Foundation Trust and North Tees and Hartlepool NHS Trust for their help in compiling information for this paper.

\section{References}

1. No authors listed. Department of Health. Delivering the NHS plan: next steps on investment: next steps on reform. http://www.dh.gov.uk/en/PublicationsandStatistics/ Publications/PublicationsAndGuidance/DH_40 (date last accessed 5 August 2007).

2. Newbold D. How to save the NHS. Nurs Stand 2006;20:20-3.

3. Schreyogg J, Stargardt T, Tiemann O, Busse R. Methods to determine reimbursement rates for diagnosis related groups (DRG): a comparison of nine european countries. Health Care Manag Sci 2006;9:215-23.

4. Busse R, Schreyogg J, Smith PC. Hospital case payment systems in Europe. Health Care Manag Sci 2006;9:211-13.

5. No authors listed. The information centre. HRG4 questionnaire: the debrief report. www.ic.nhs.uk/webfiles/Services/casemix/prev\%20HRG4HRG4\%20questionnaire\% 202006.doc (date last accessed 5 August 2007).

6. No authors listed. NHS Information Authority: Clinical Coding Instruction Manual. September 2000. http://www.connectingforhealth.nhs.uk/systemsandservices/data/ clinicalcoding/icd10_OPCS4_man (date last accessed 5 August 2007).
7. No authors listed. DoH. Chief Executive report to the NHS. DoH, June 2006. http:// www.dh/gov.uk/en/publicationsandstatistics/publications/publicationsPolicyAndGuidance/DH_4135795 (date last accessed 5 August 2007).

8. No authors listed. Implementing the new system of financial flows: payment by results: technical guidance 2003/4. London. DoH, 2002. http://www.dh.gov.uk/en/Publicationsandstatistics/Publications/PublicationsPolicyAndGuidance/DH_4007466 (date last accessed 5 August 2007).

9. Newbold D. Caring about the costs. Nurs Stand 2006;20:24-5.

10. No authors listed. DoH: financial management in the NHS. DoH, March 2007. http:// www.library.nhs.uk/healthmanagement/ViewResource.aspx?resID=260219 (date last accessed 5 August 2007).

11. No authors listed. DoH: issues concerning quality of clinical coding. www.performance.doh.gov.uk/nhsperformanceandindicators/2002/issues.html (date last accessed 5 August 2007).

12. No authors listed. $\mathrm{PbR}$ head pledges to tackle tariff problems. BMJ News 2007:2.

13. Jameson SS, Nargol AVF, Reed MR. Payment by results for patients with fractured neck of femur in two NHS secondary care trusts. Ann $R$ Coll Surg Eng (Suppl) 2007;89:310-12

14. Rogers R, Williams $\mathbf{S}$, Jarman B, Aylin $\mathbf{P}$. "HRG drift" and payment by results. BMJ 2005;330:563

15. Day M. NHS faces job cuts as financial crisis deepens. BMJ 2006;332:743.

16. No authors listed. DoH Chief Medical Officer. Good doctors, safer patients. http:// www.dh.gov.uk/en/PublicationsandStatistics/Publications/PublicationsPolicyAndGuidance/DH_4137232 (date last accessed 5 August 2007).

17. No authors listed. Dr. Foster Intelligence. How healthy is your hospital? http:// www.drfoster.co.uk/library/reports/hospitalGuide2007.pdf (date last accessed 5 August 2007).

18. No authors listed. Department of Health. Payment by results: tariff information. http:/ /www.dh.gov.uk/en/Policyandguidance/Organisationpolicy/Financeandplanning/NHSFinancialReforms/DH_077279 (dated last accessed 7 October 2007).

19. Lemon $\mathbf{M}$, Hamilton $\mathbf{P}$, Field $\mathbf{R}$. The cost of total hip replacement and total knee replacement: a comparison with national tariff. BON 2007;35:47-9.

20. Street A, Lowson K. Do tariffs stack up? Health Serv J 2004;114:31.

21. Bozic KJ, Katz P, Cisternas M, et al. Hospital resource utilisation for primary and revision total hip arthroplasty. J Bone Joint Surg [Am]2005;87-A:570-6.

22. No authors listed. Demand management and administrative costs under payment by results. Health Policy Matters. Issue 12 Oct 2006. http://www.york.ac.uk/healthsciences/pubs/hpm12.pdf (date last accessed 5 August 2007).

23. No authors listed. Audit Commission: early lessons from payment by results. London: Audit Commission, 2005. http://www.audit_commission.gov.uk/reports/NATIONALREPORT.asp?CategoryID=ENGLISH\%5E574\&PROdID=B502FOFC-E007-4925=AD24529C4889AD02\&SECTIONID=sect1 (date last accessed 5 August 2007).

24. No authors listed. Engaging clinicians in improving data quality in the NHS. http:/ www.replondon.ac.uk/documents/EngagingCliniciansDataQualityNHS.pdf (date last accessed 5 August 2007).

25. O'Connor RJ, Neumann VC. Payment by results or payment by outcome?: the history of measuring medicine. JR Soc Med 2006;99:226-31.

26. No authors listed. DoH connecting for health. http://www.connectingforhealth. nhs.uk (date last accessed 1 October 2007). 